\title{
Two Layer Constant Power Control of DFIG Wind Turbines with Super Capacitor Energy Storage
}

\author{
A. Sharath kumar ${ }^{*}$, M. Rakesh ${ }^{2}$, V.Kiranmai ${ }^{3}$, V. supritha $^{4}$ \\ ${ }^{*}$ (Assistant professor, Department of EEE, Kamala institute of technology and science, India). \\ ${ }^{2}$ (Assistant professor, Department of EEE, Kamala institute of technology and science, India). \\ ${ }^{3}$ (Assistant professor, Department of EEE, Kamala institute of technology and science, India). \\ ${ }^{4}$ (Assistant professor, Department of EEE, Kamala institute of technology and science, India).
}

\begin{abstract}
To dynamically match the intermittency of wind energy, energy storage devices will be required. In this project a two-layer constant power control scheme for a wind farm equipped with doubly fed induction generator (DFIG) wind turbine is considered. In the two layer control, there is a high layer controller known as Wind farm supervisory control (WFSC), which generates Active power (P), Stator power (Ps), Energy storage power (Pe), DC voltage (Vdc) etc. references for the low layer Wind turbine generator (WTG) controllers, according to the power demand from the grid operator. The low layer wind turbine generator(WTG) controller consist of Rotor side converter control and Grid side converter control to regulate each Double fed induction generator (DFIG) wind turbine, to generate desired amount of active power, Where the deviations between the available wind energy input and desired active power output are compensated by Super capacitor Energy storage system. Simulation is carried out in a MATLAB/SIMULATION to evaluate the performance of wind farm equipped with 15 DFIG wind turbines with and without energy storage system to provide a constant active power of $36 \mathrm{MW}$.
\end{abstract}

Keywords: Constant power control (CPC), Supercapacitor Energy storage system, Wind farm supervisory control, Wind Turbine Generator Contollers, doubly fed induction generator (DFIG).

\section{Introduction}

When wind turbines are connected to a grid, they should always maintain a constant power. In order to maintain a constant active power, the use of Double-Fed Induction generators(DFIG) with energy storage system like super capacitors can be used with a two-layer constant power control scheme [1].Wind turbine generators (WTGs) are usually controlled to generate maximum electrical power from wind under normal wind conditions. The European Wind Energy Association has set a target to satisfy more than 22\% of European electricity demand with wind power by 2030 [2]. To enable WTGs to effectively participate in frequency and active power regulation, unit commitment, energy storage devices will be required to dynamically match the intermittency of wind energy [3]. Pumped water \& compressed air are the most commonly used energy storage technologies for power grids due to their low capital costs [4]. Compared to batteries, supercapacitors have a higher power density, higher round-trip efficiency, longer cycle life, and lower capital cost per cycle [5]. This paper proposes considered a two-layer constant power control (CPC) scheme for a wind farm with a DFIG wind turbines.

\section{System Description}

DFIG wind turbine with energy storage

Fig. 1 shows the basic configuration of a DFIG wind turbine equipped with a super capacitor-based ESS. The low-speed wind turbine drives a high-speed DFIG through a gearbox. The DFIG is a wound-rotor induction machine. It is connected to the power grid at both stator and rotor terminals. The stator is directly connected to the grid, while the rotor is fed through a variable-frequency converter, which consists of a rotorside converter (RSC) and a grid-side converter (GSC) connected back to back through a dc link and usually has a rating of a fraction $(25 \%-30 \%)$ of the DFIG nominal power.

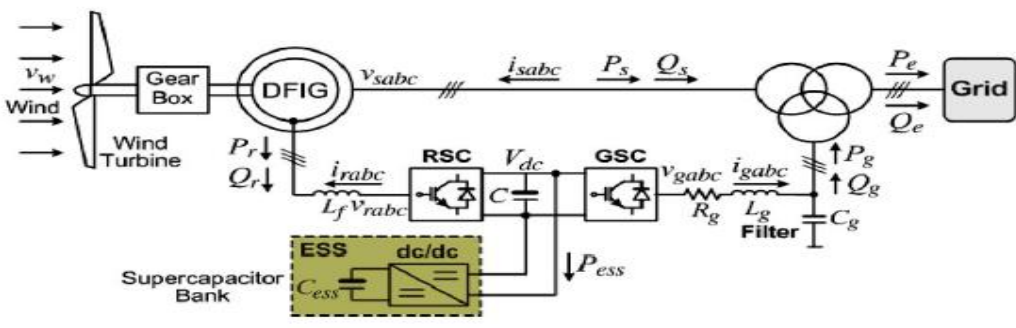

Fig -1: Configuration of a DFIG wind turbine equipped with a ESS connected to a grid. 
An ESS consisting of a super capacitor bank and a two-quadrant dc/dc converter is connected to the dc link of the DFIG converters. The ESS serves as either a source or a sink of active power and therefore contributes to control the generated active power of the WTG. The value of the capacitance of the super capacitor bank can be determined by

$$
\mathrm{C}_{\mathrm{Ess}}=\frac{2 \mathrm{P}_{\mathrm{n}} \mathrm{T}}{\mathrm{V}_{\mathrm{SC}}^{2}}
$$

\section{Control of Individual DFIG Wind Turbine: \\ Control of the RSC:}

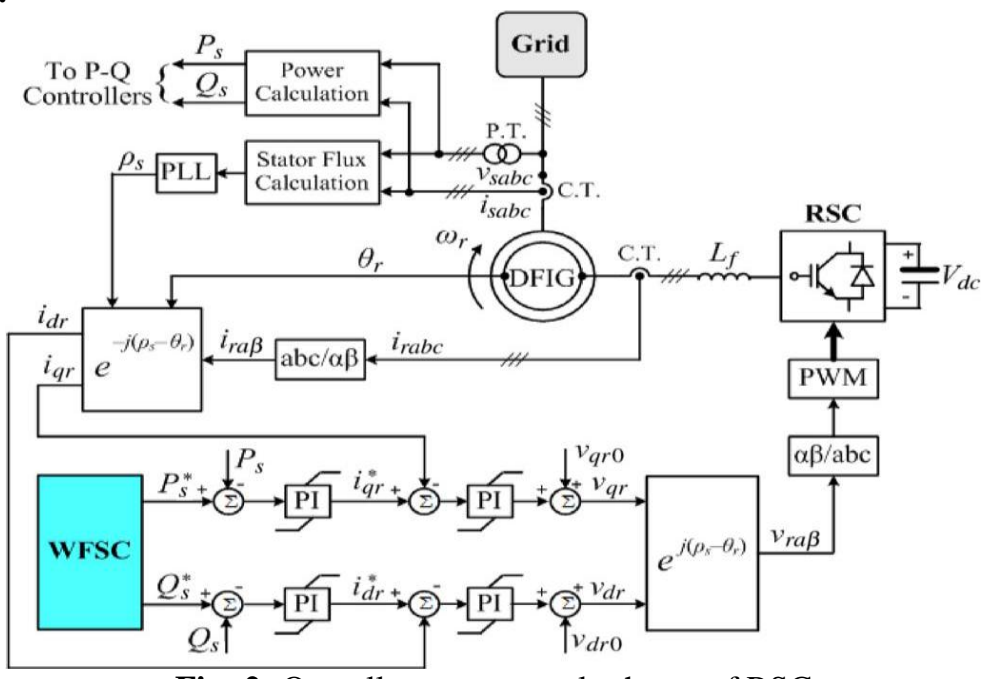

Fig -2: Overall vector control scheme of RSC

Fig. 2 shows the overall vector control scheme of the RSC, in which the independent control of the stator active power $P s$ and reactive power $Q s$ is achieved by means of rotor current regulation in a stator-flux oriented synchronously rotating reference frame. Therefore, the overall RSC control scheme consists of two cascaded control loops. The outputs of the two current controllers are compensated by the corresponding crosscoupling terms $v_{d r 0}$ and $v_{q r 0}$, respectively, to form the total voltage signals $v_{d r}$ and $v_{q r}$. They are then used by the PWM module to generate the gate control signals to drive the RSC.

\section{Control of the GSC:}

Fig. 3 shows the overall vector control scheme of the GSC, in which the control of the dc-link voltage $V_{\mathrm{dc}}$ and the reactive power $Q_{g}$ exchanged between the GSC and the grid is achieved by means of current regulation in a synchronously rotating reference frame. Again, the overall GSC control scheme consists of two cascaded control loops. The outputs of the two current controllers are compensated by the corresponding cross coupling terms $v_{d g 0}$ and $v_{q g 0}$, respectively, to form the total voltage signals $v_{d g}$ and $v_{q g}$. They are then used by the PWM module to generate the gate control signals to drive the GSC. The reference signal of the outer-loop reactive power controller is generated by the high-layer WFSC.

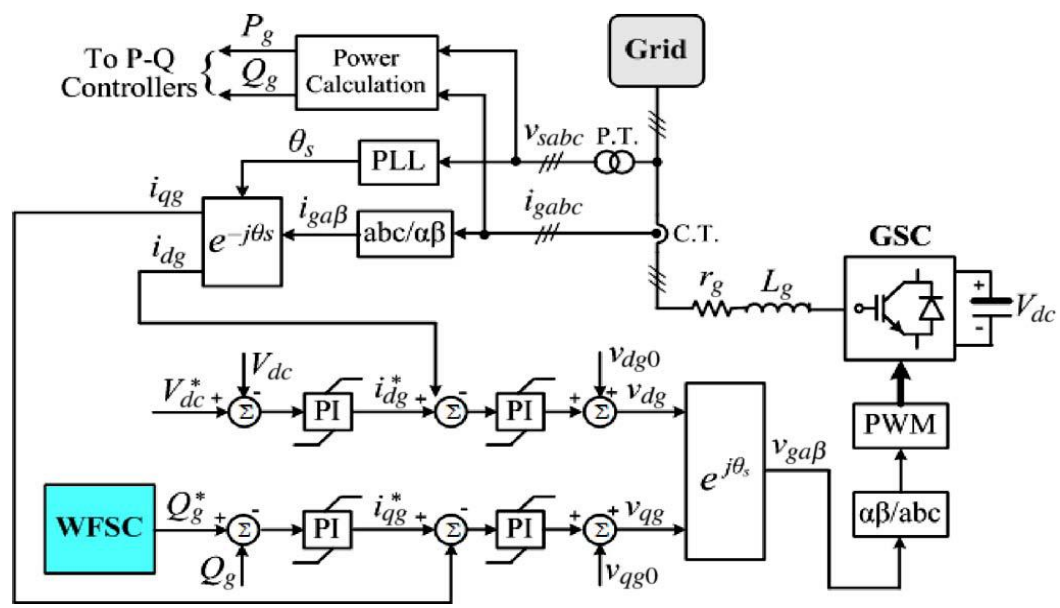

Fig -3: Overall vector control scheme of the GSC 


\section{Configuration and Control of the ESS:}

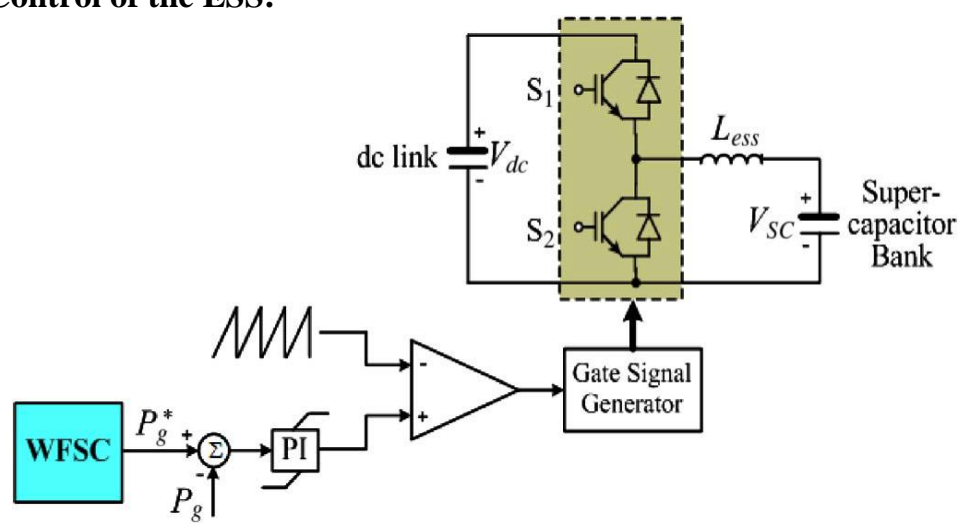

Fig -4: Configuration and control of the ESS

Fig. 4 shows the configuration and control of the ESS. The ESS consists of a super capacitor bank and a two-quadrant $\mathrm{dc} / \mathrm{dc}$ converter connected to the dc link of the DFIG. The dc/dc converter contains two insulated-gate bipolar transistor (IGBT) switches S1 and S2. If S1 is open, the dc/dc converter operates in the boost mode; if $\mathrm{S} 2$ is open, the dc/dc converter operates in the buck mode. The duty ratio $D_{1}$ of $\mathrm{S} 1$ in the buck mode can be approximately expressed as

$$
\mathrm{D}_{1}=\frac{\mathrm{V}_{\mathrm{SC}}}{\mathrm{V}_{\mathrm{dc}}}
$$

And the duty ratio $D_{2}$ of $\mathrm{S} 2$ in the boost mode is $D_{2}=1-D_{1}$.

\section{Wind Turbine Blade Pitch Control:}

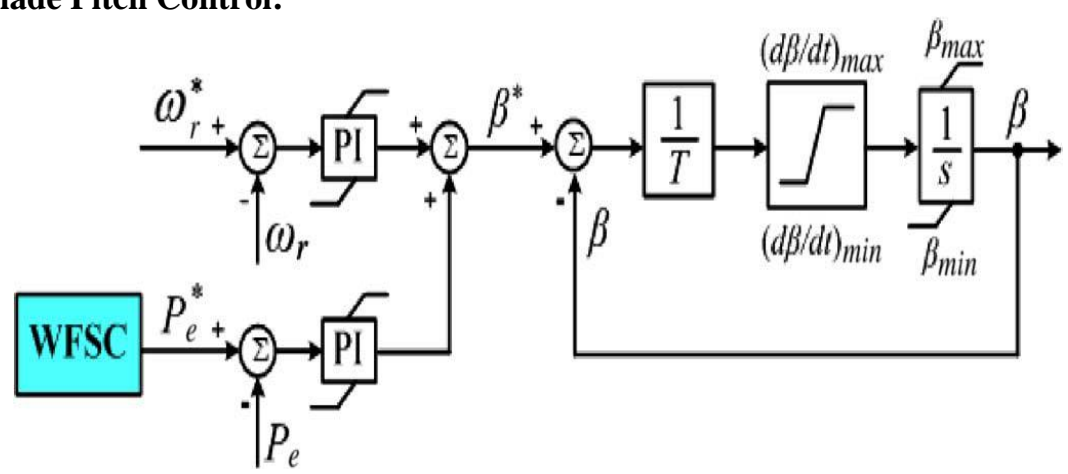

Fig -5: Blade pitch control for the wind turbine

Fig. 5 shows the blade pitch control for the wind turbine, where $\omega_{r}$ and $P_{e}\left(=P_{s}+P_{g}\right)$ are the rotating speed and output active power of the DFIG, respectively. When the wind speed is below the rated value and the WTG is required to generate the maximum power, $\omega_{r}$ and $P_{e}$ are set at their reference values, and the blade pitch control is deactivated. When the wind speed is below the rated value, but the WTG is required to generate a constant power less than the maximum power, the active power controller may be activated.

\section{Wind Farm Supervisory Control (WFSC)}

The objective of the WFSC is to generate the reference signals for the outer-loop power controllers of the RSC and GSC, the controller of the dc/dc converter, and the blade pitch controller of each WTG, according to the power demand from or the generation commitment to the grid operator. The implementation of the WFSC is described by the flowchart in Fig: 6, where $P_{d}$ is the active power demand from or the generation commitment to the grid operator; $v_{w i}$ and $V_{\text {essi }}$ are the wind speed in meters per second and the voltage of the supercapacitor bank measured from WTG $i(i=1, \ldots, N)$, respectively; and $N$ is the number of WTGs in the wind farm. Based on $v_{w i}$, the optimal rotational speed $\omega_{t i}$, opt in radians per second of the wind turbine can be determined, which is proportional to the wind speed $v_{w i}$ at a certain pitch angle $\beta_{i}$

$$
\omega_{\text {ti. opt }}=k\left(\beta_{i}\right) v_{\text {wi }}
$$

Where $k$ is a constant at a certain value of $\beta_{i}$, then the maximum mechanical power $P_{m i \text { max }}$ that the wind turbine extracts from the wind can be calculated by the well-known wind turbine aerodynamic characteristics

$$
P_{\text {mi max }}=\frac{1}{2} \rho_{i} A_{r} v_{0 i}^{a} C_{P_{i}}\left(p_{\text {topt }} \cdot P_{i}\right)
$$




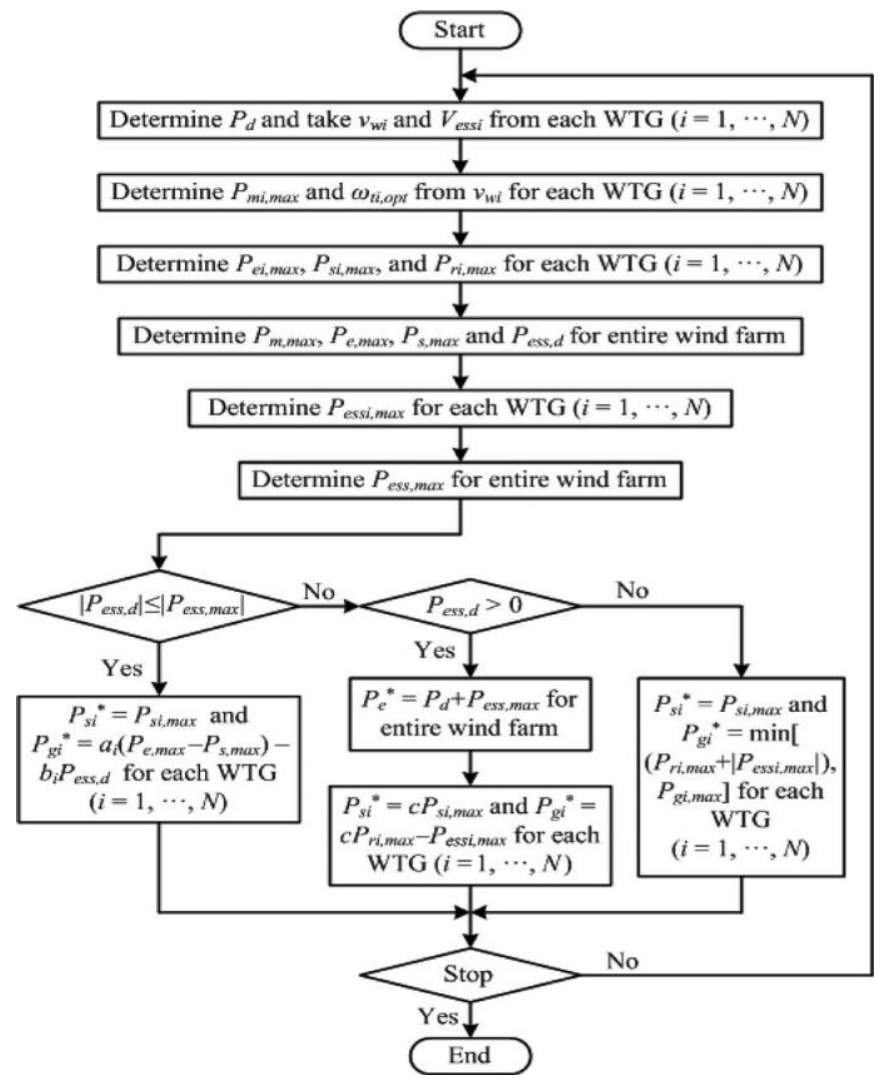

Fig -6: Flowchart of implementation of the WFSC

where $\rho_{i}$ is the air density in kilograms per cubic meter; $A_{r}=\pi R^{2}$ is the area in square meters swept by the rotor blades, with $R$ being the blade length in meters; and $C_{P i}$ is the power coefficient, which is a function of both tip-speed ratio $\lambda_{i}$ and the blade pitch angle $\beta_{i}$, where $\lambda_{i}$ is defined by

$$
\lambda_{\mathrm{i}}=\frac{\omega_{\mathrm{ti}} \mathrm{R}}{v_{\mathrm{wi}}}
$$

In (4), $\lambda_{i, \text { opt }}$ is the optimal tip-speed ratio when the wind turbine rotates with the optimal speed $\omega_{t i, \text { opt }}$ at the wind speed $v_{w i}$. Given $P_{m i \text { max }}$, the maximum active power $P_{e i, \max }$ generated by the WTG can be estimated by taking into account the power losses of the WTG

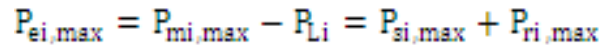

Where $P_{L i}$ is the total power losses of WTG $i$, which can be estimated by the method in; $P_{s i \text { max }}$ and $P_{r i, \max }$ are the maximum DFIG stator and rotor active powers of WTG $i$, respectively. The stator active power $P_{s}$ can be written in a synchronously rotating $d q$ reference frame as follows:

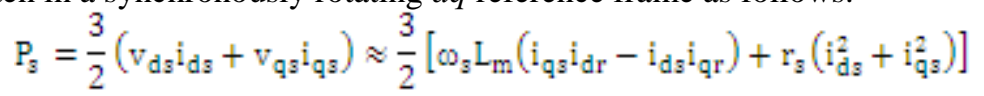

where $v d s$ and $v q s$ are the $d$ - and $q$-axis voltage components of the stator windings, respectively; ids and iqs are the stator $d$ - and $q$-axis current components, respectively; $i d r$ and iqr are the rotor $d$ - and $q$-axis current components, respectively; $\omega s$ is the rotational speed of the synchronous reference frame; and $r s$ and $L m$ are the stator resistance and mutual inductance, respectively. Similarly, the rotor active power is calculated by

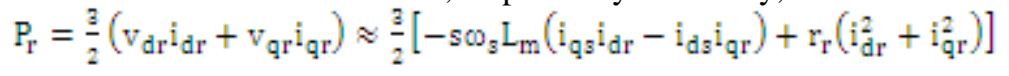

where $v d r$ and $v q r$ are the $d$ - and $q$-axis voltage components of the rotor windings, respectively; $s$ is the slip of the DFIG defined by

$$
s=\left(\omega_{s}-\oplus_{\mathrm{r}}\right) / \omega_{8}
$$

Where $\omega r$ is the DFIG rotor speed. (7) And (8) yield

Where

$$
\mathrm{s}=-\frac{\mathrm{P}_{\mathrm{r}}-\mathrm{ai} \mathrm{P}_{\mathrm{r}}^{\mathrm{R}_{\mathrm{r}}}}{\mathrm{P}_{\mathrm{s}}-\mathrm{ai} \mathrm{I}_{\mathrm{r}}}
$$

$\mathfrak{I}_{s}=\sqrt{\mathbb{1}_{\mathrm{ds}}^{2}+\mathrm{i}_{\mathrm{qq}}^{2} / 2}$ and $\mathfrak{1}_{\mathrm{r}}=\sqrt{\mathrm{i}_{\mathrm{dr}}^{2}+\mathrm{i}_{\mathrm{qq}}^{2} / 2}$ 
If neglecting the stator copper loss $3 i_{s}^{2} r_{s}$ and rotor copper loss $3 i_{r}^{2} r_{r}$ of the DFIG, the relationship between the stator and rotor active powers can be approximated by

$$
\mathrm{P}_{\mathrm{r}}=-\mathrm{sP}_{\mathrm{g}}
$$

According to (6) and (10) [or (11)], $P_{s i, \max }$ and $P_{r i, \max }$ of each WTG can be determined.

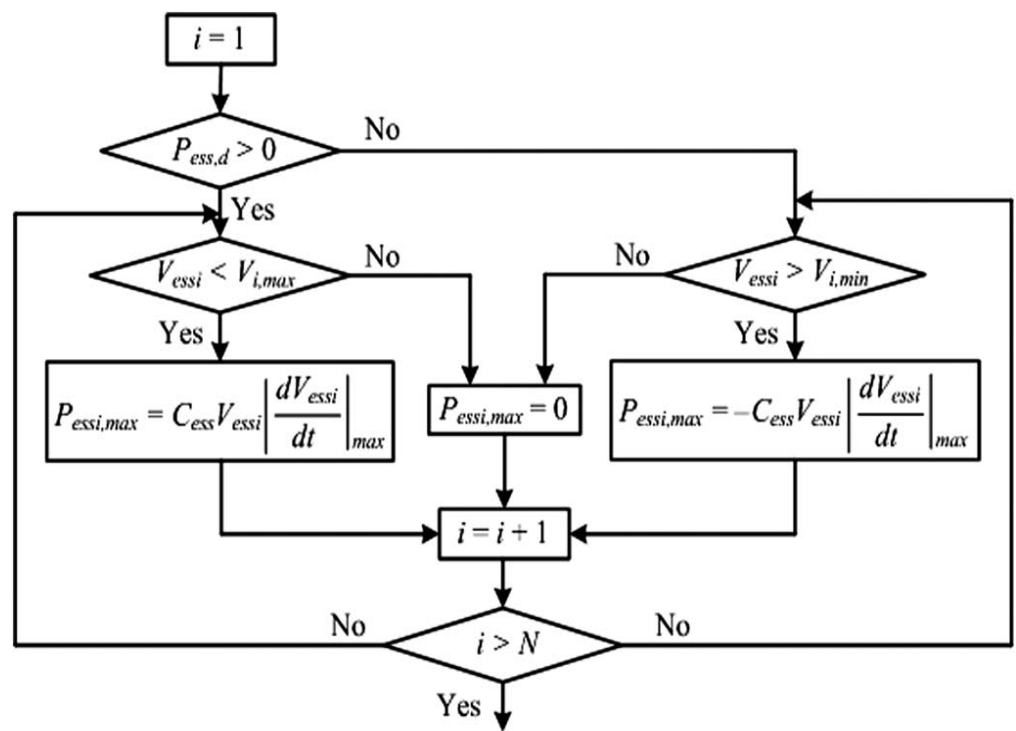

Fig -7: Flowchart of determination of $P_{\text {essi,max }}$ for each WTG

Then, the total maximum mechanical power $P_{m, \max }$, DFIG output active power $P_{e, \max }$, and stator active power $P_{s, \max }$ of all WTGs in the wind farm can be calculated as

$$
\begin{aligned}
& \mathbb{P}_{\mathrm{m}_{\text {max }}}=\sum_{\mathrm{i}=1}^{\mathbb{N}} \mathrm{P}_{\text {mi max }} \\
& P_{\mathbb{E}_{i} \max }=\sum_{\mathrm{i}=1}^{\mathbb{N}} P_{\mathrm{e}_{\mathrm{i}} \max } \\
& P_{8 \text { max }}=\sum_{i=1}^{\mathbb{N}} P_{\text {si max }}
\end{aligned}
$$

In order to supply constant power $P_{d}$ to the grid, the deviation $P_{\text {ess }, d}$ between the demand/commitment $P_{d}$ and the maximum generation $P_{e, \max }$ is the power that should be stored in or supplied from the ESSs of the WTGs

$$
P_{E B s} d=P_{e \max }-P_{d}
$$

During normal operation, $\mathrm{V}_{\text {essi }}$ must be maintained within the following range:

$$
\mathrm{V}_{\mathrm{imin}}<\mathrm{V}_{\mathrm{essi}}<\mathrm{V}_{\mathrm{i} \max }
$$

The maximum power $P_{\text {essi, max }}$ that can be exchanged between the supercapacitor bank and the DFIG dc link of WTG $i$ can be determined by

$$
P_{\text {essi_max }}= \pm C_{\text {ess }} W_{\text {essi }} \| \frac{d W_{\text {argi }}}{d t} \max \mid
$$

Where $\left|d V_{\text {essi }} / d t\right|_{\max }$ is the maximum rate of voltage variations of the supercapacitor bank, which is related to the current limits of the supercapacitor bank. In (17), the positive sign indicates storing energy, while the negative sign indicates supplying energy by the ESS. The calculation of $P_{\text {essi, } \max }$ for each WTG is subjected to (16). Fig: 7 shows how to determine $P_{\text {essimax }}$ for each WTG. If $P_{\text {ess }, d}>0$, extra power needs to be stored in the ESSs. In this case, if $V_{\text {essi }}<V_{i, \max }, P_{\text {essi,max }}$ is calculated by (17) and takes the positive sign; otherwise, the ESS cannot store any power and $P$ essi, $\max =0$. On the contrary, if ${ }_{\text {Pess, } d}<0$, active power needs to be supplied from the ESSs. In this case,If $V_{\text {essi }}>V_{i, \min }, P$ essi, max is calculated by (17) and takes the negative sign; otherwise, the ESS cannot supply any power and $P_{\text {essi, } \max }=0$. As shown in Fig: 6, once $P_{\text {essi, } \max }$ of each WTG is determined, the total maximum power $P_{\text {ess, max }}$ that can be exchanged between the supercapacitor bank and the DFIG dc link of all WTGs can be determined by

$$
P_{E B B_{\text {max }}}=\sum_{\mathrm{i}=1}^{\mathbb{N}} \mathrm{P}_{\mathrm{EBSi} \max }
$$


Finally, depending on the relationship of $P_{\text {ess, } d}$ and $P_{\text {ess, max }}$, the reference signals $P_{s i}^{*}$ (see Fig:5.2) and $P^{*}{ }_{g i}$ (see Fig:5.4) of each WTG can be determined. Specifically, if $\left|P_{\text {ess }, d}\right| \leq\left|P_{\text {ess, max }}\right|, \quad P^{*}{ }_{s i}$ and $P^{*}{ }_{g i}$ can be determined directly, as shown in Fig:5.6, where the partition coefficients ai's are calculated by

$$
\mathrm{a}_{\mathrm{i}}=\frac{P_{\mathrm{ri} \max }}{P_{\mathrm{z} \text { max }}-P_{\mathrm{x} \text { max }}}
$$

And the partition coefficients $b i$ 's are calculated by

$$
b_{i}=\frac{P_{\text {essi max }}}{\mathbb{P}_{\text {eEs } \max }}
$$

The coefficients $a i$ and $b i$ have the following feature:

$$
\sum_{\mathrm{i}=1}^{\mathbb{N}} a_{\mathrm{i}}=1 \quad \sum_{\mathrm{i}=1}^{\mathbb{N}} b_{\mathrm{i}}=1
$$

If $\left|P_{\text {ess, }, d}\right|>\left|P_{\text {ess, } \max }\right|$, depending on the sign of $P_{\text {ess, }, d}, P^{*}{ }_{s i}$ and $P^{*}{ }_{g i}$ can be determined, as shown in Fig. 6. If $P$ ess, $d$ is positive, the ESSs of the WTGs store active power, and the total active power generated by all DFIGs is $P_{e}^{*}$, which is less than $P_{e, \max }$. Therefore, a scaling factor $c$ is defined as follows:

$$
\mathrm{c}=\frac{\mathrm{P}_{\mathrm{e}}^{*}}{\mathrm{P}_{\mathfrak{e} \max }}
$$

And $P^{*}{ }_{s i}$ and $P^{*}{ }_{g i}$ can be determined by using the scaling factor. If $P_{\text {ess }, d}$ is negative, the ESSs of the WTGs supply active power, the RSC of each WTG is controlled to generate the maximum stator active power $P_{s i, \max }$, and the ESS of each WTG is controlled to generate active power of $P^{*}{ }_{g i}$,

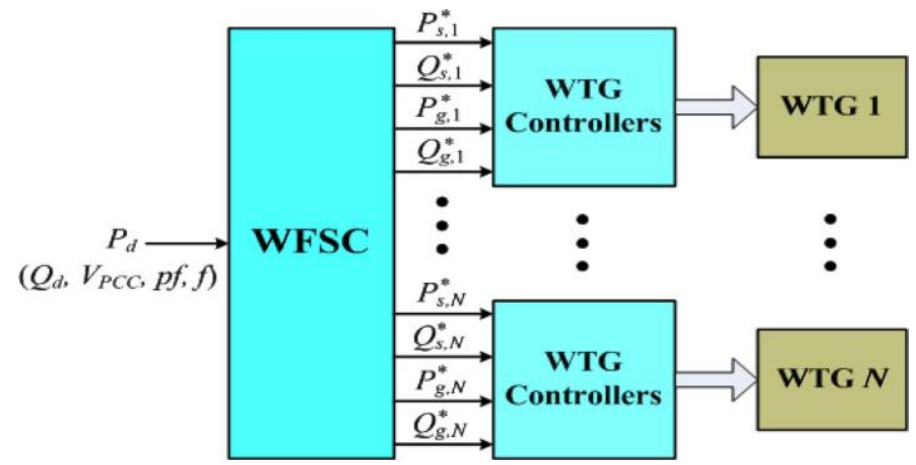

Fig -8: proposed two-layer CPC scheme for the wind farm.

Fig. 8 shows the block diagram of the proposed two-layer CPC scheme for the wind farm. In practice, the value of $P d$ should take into account the generation capability of the wind farm and should be subjected to the following limit:

$$
\mathrm{P}_{\mathbb{d}} \leq \overline{\mathrm{P}}_{\mathrm{E} \max }
$$

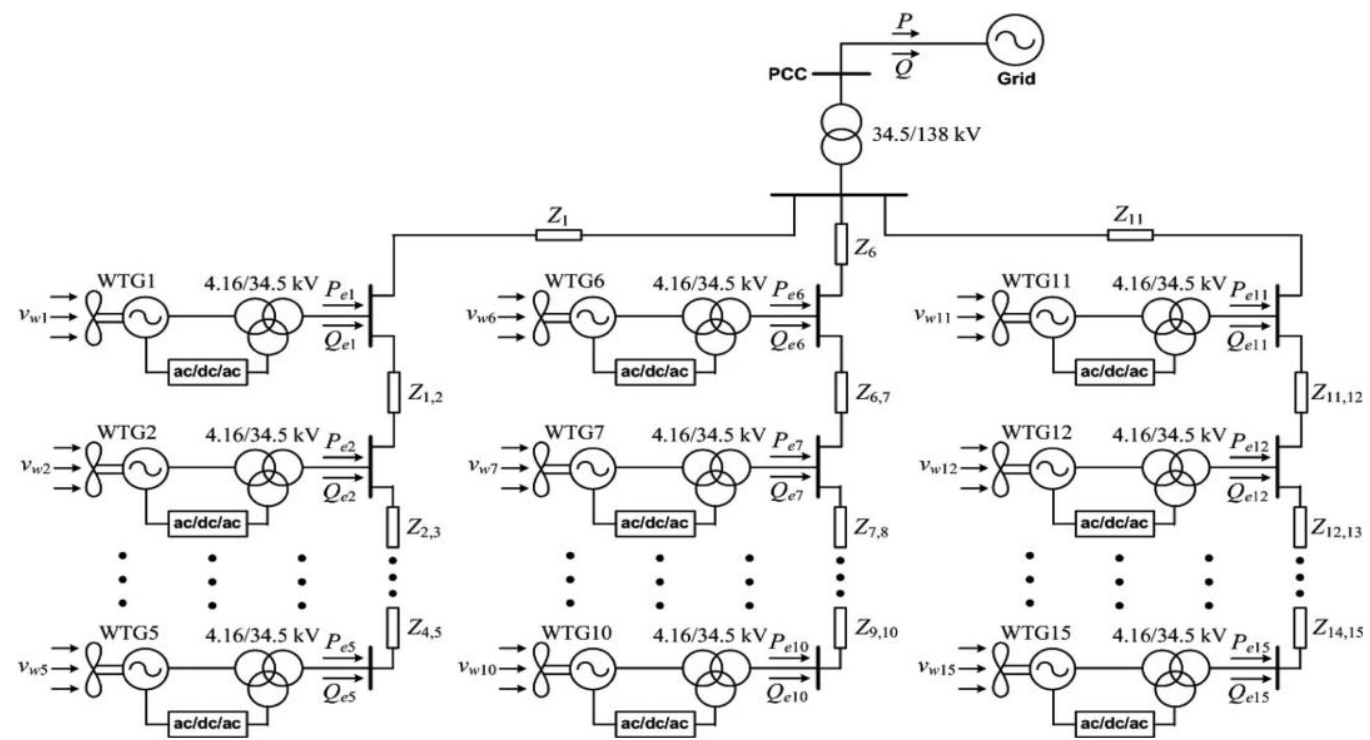

Fig -9: Configuration of a wind farm equipped with 15 DFIG wind turbines connected to a grid. 
The reactive power references of the RSC and GSC controllers can be determined by controlling the power factor ( $p f$ ) or the voltage (VPCC) at the point of common coupling (PCC) of the wind farm at the desired value or to supply a desired amount of reactive power as required by the grid operator.

\section{Simulation Results}

Simulation studies are carried out for a wind farm with 15 DFIG wind turbines to verify the effectiveness of the proposed control scheme under various operating conditions. Each DFIG wind turbine has a 3.6MW power capacity. The total power capacity of the wind farm is $54 \mathrm{MW}$.

\section{CPC during Variable Wind Speed Conditions}

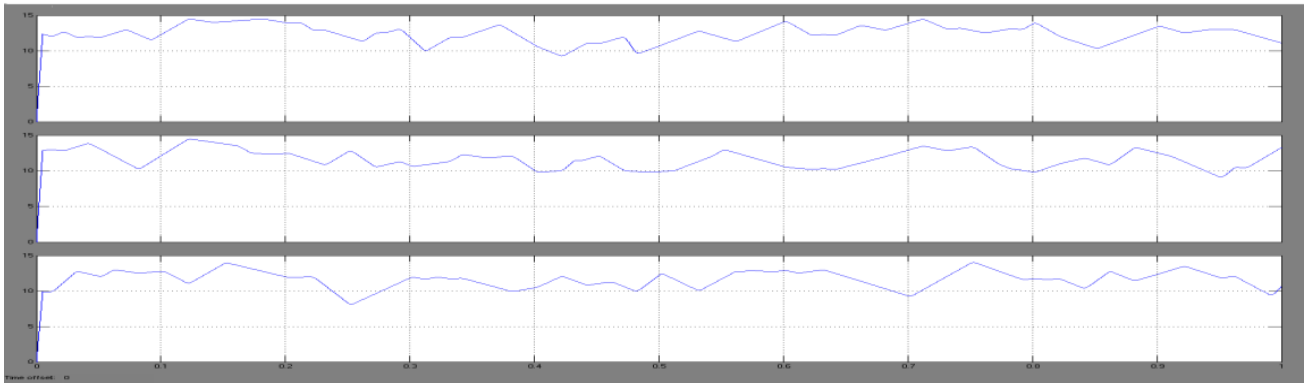

Fig: 10 Wind speed profiles of WTG1, WTG6, and WTG11

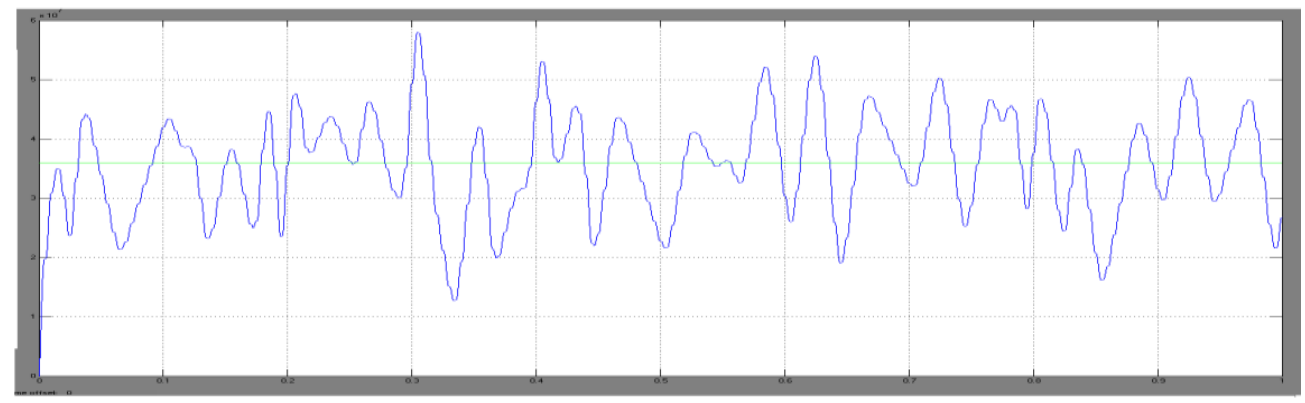

Fig: 11 Comparison of the wind farm power output and constant power demand Without ESS

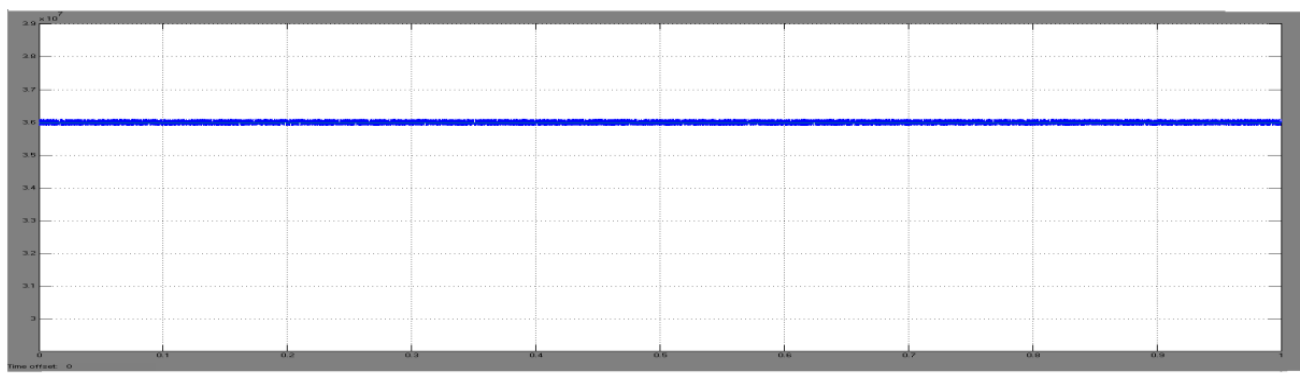

Fig: 12 Comparison of the wind farm power output and the constant power demand from or commitment to the grid operator: With ESSs and the proposed CPC scheme.

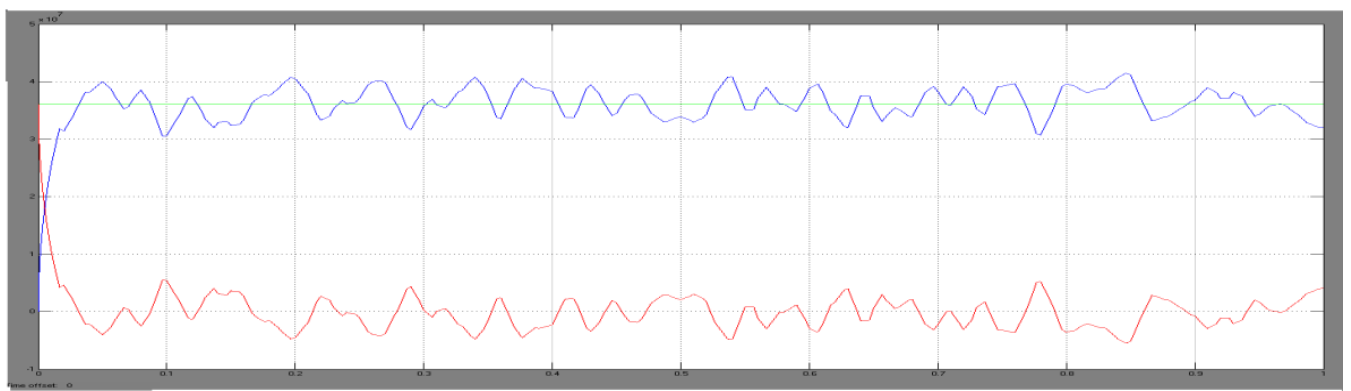

Fig: 13 Active powers of all WTGs and the wind farm 


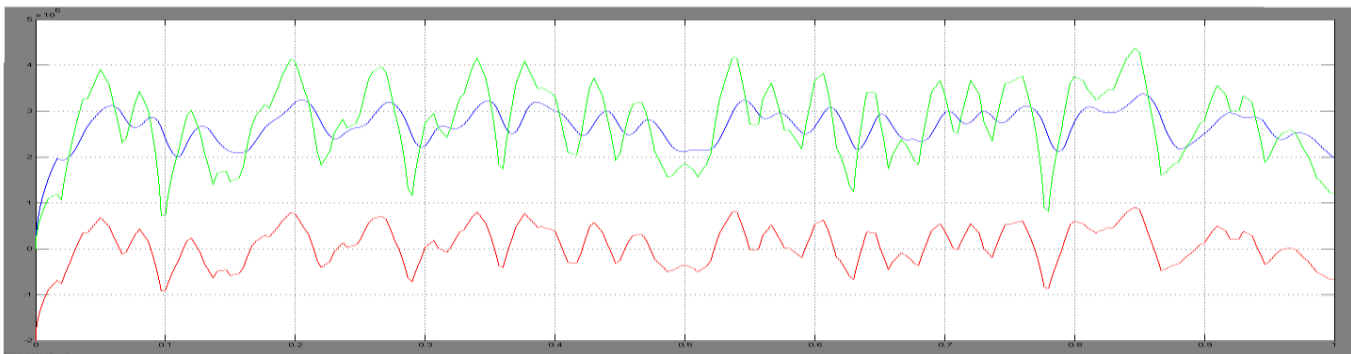

Fig: 14 Stator active power (Ps1), GSC active power (Pg1) \& total active power output (Pe1) of WTG1.

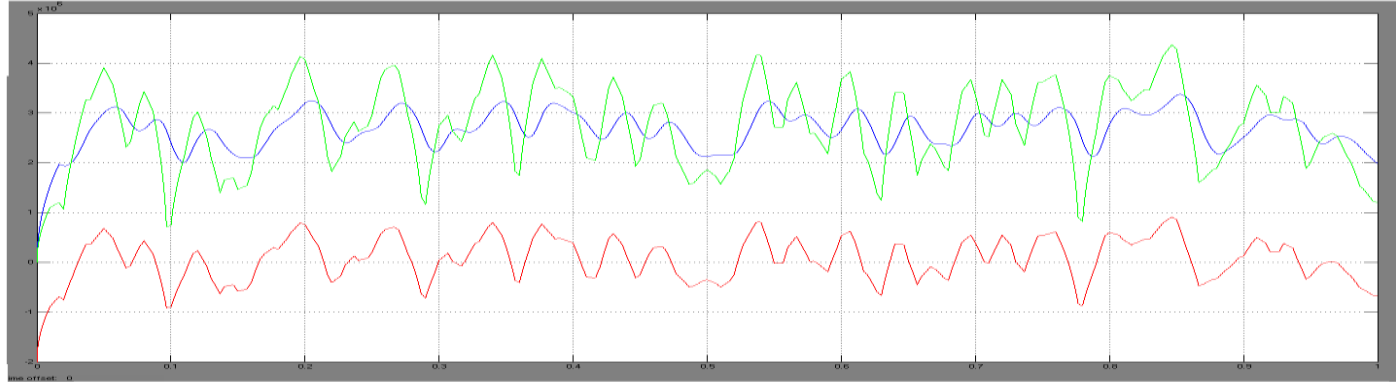

Fig: 15 Stator active power (Ps6), GSC active power (Pg6) \& total active power output (Pe6) of WTG6

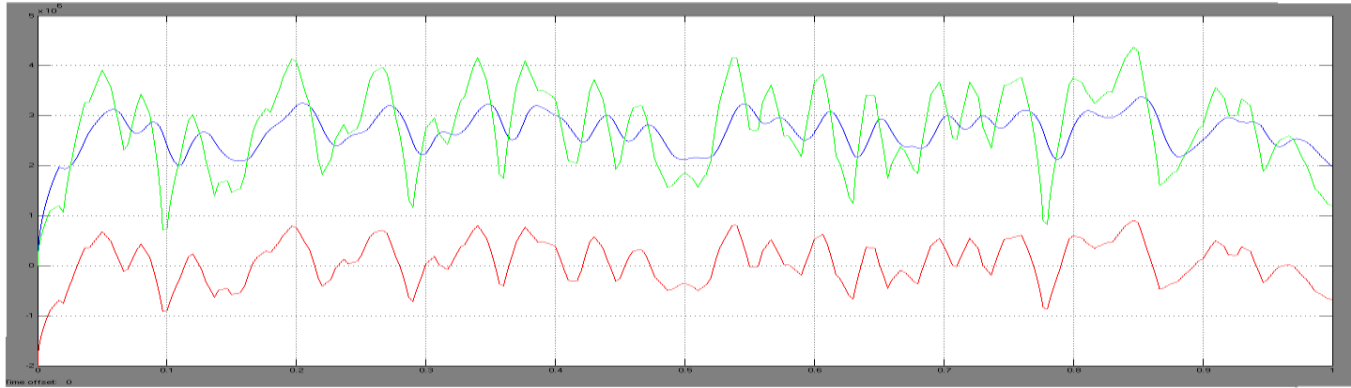

Fig: 16 Stator active power (Ps11), GSC active power (Pg11) \& total active power output (Pe11) of WTG11

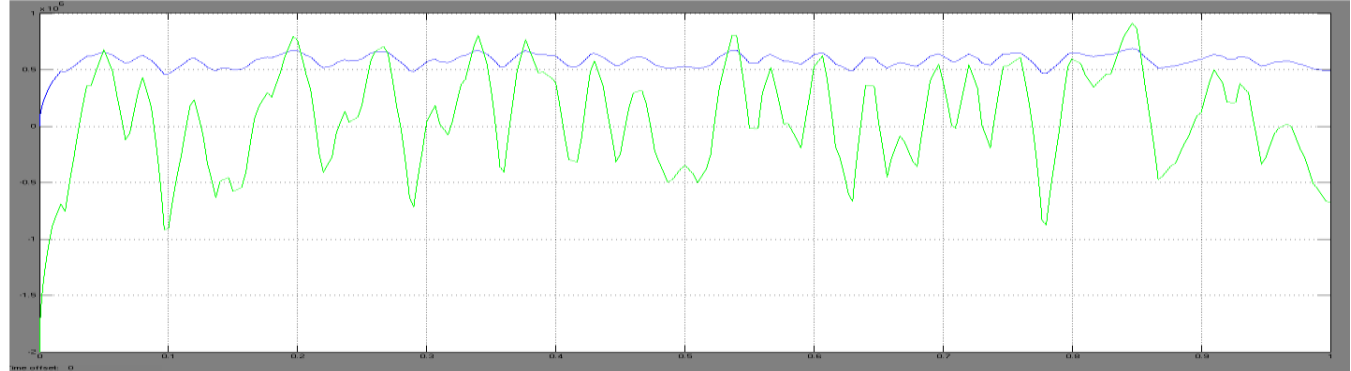

Fig: 17 Rotor active power (Pr1) \& active power stored/supplied by the ESS (Pess1) of WTG1

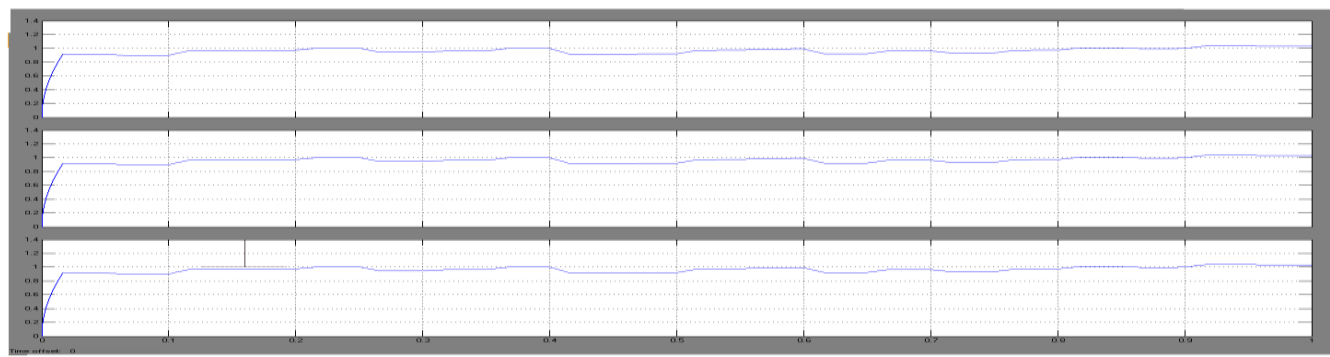

Fig: 18 Voltages of the super capacitor banks of WTG1, WTG6, and WTG11 


\section{Power Tracking During Step Changes in Demand/Commitment}

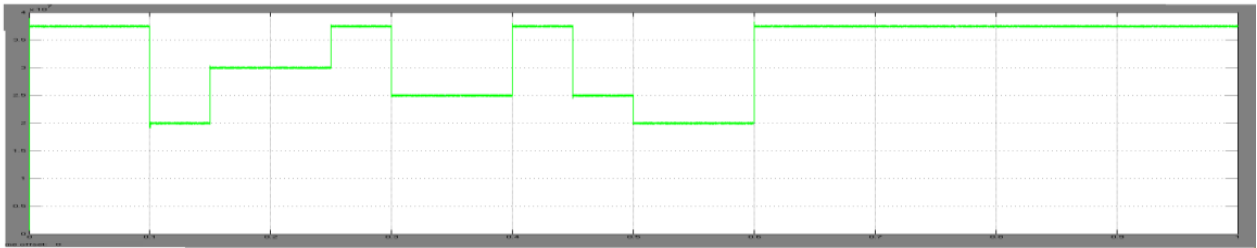

Fig:19 Power tracking performance of the wind farm during step changes in demand from or commitment to the grid operator

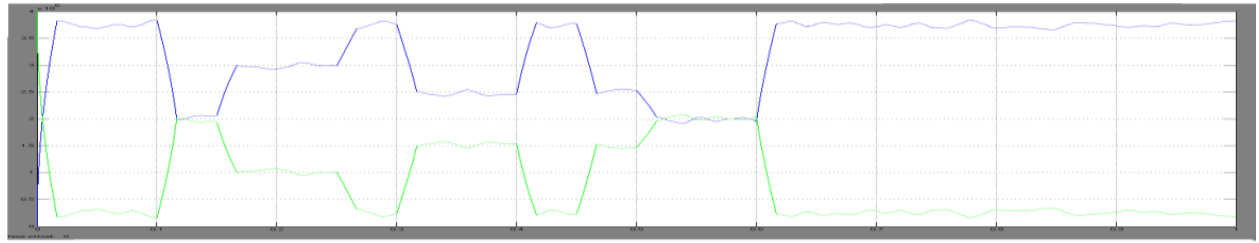

Fig: 20 Total active power outputs of WTG1 (Pe1) and WTG5 (Pe5) during step changes in demand from or commitment to the grid operator.

\section{Conclusion}

In this paper, a two-layer Constant Power Control scheme for a wind farm equipped with 15 DFIG wind turbine is considered. The WFSC generates the active power references for the low-layer WTG controllers according to the active power demand from or generation commitment to the grid operator; the low-layer WTG controllers then regulate each DFIG wind turbine to generate the desired amount of active power, where the deviations between the available wind energy input and desired active power output are compensated by the ESS.

In this paper, Energy storage system serves as either a source or a sink of active power to control the generated active power of the DFIG wind turbine. Power electronic devices Rotor side converter, Grid side converter and DC/DC converter are promising technical solutions to provide wind power installations with power system control capabilities and to improve their effect on power system stability. Simulation studies are carried out in MATLAB/SIMULATION on a wind farm equipped with 15 DFIG wind turbines to verify the effectiveness of the proposed control scheme.

\section{Future Scope}

This project has unlocked many gates for the future young engineers to install the wind power plants to fulfill the gap between the current power generations and future power demand needed. Now the penetration of wind power to the power grids is $1-2 \%$ of nations power by the use of advanced energy storage devices like Supercapacitors we can achieve $20 \%$ of wind power in nation's total power by 2030 .

\section{Proceedings Papers:}

\section{References}

[1]. Liyan Qu, Member, IEEE, and Wei Qiao, Member, IEEE, "Constant Power Control of DFIG Wind Turbines With Supercapacitor Energy Storage" VOL. 47, NO. 1, JANUARY/FEBRUARY 2011

[2]. J. P. Barton and D. G. Infield, "Energy storage and its use with intermittent renewable energy," IEEE Trans. Energy Convers., vol. 19, no. 2, pp. 441-448, Jun. 2004.

[3]. Abbey and G. Joos, "Supercapacitor energy storage for wind energy applications," IEEE Trans. Ind. Appl., vol. 43, no. 3, pp. 769-776, .May/Jun. 2007.

[4]. W. Qiao, W. Zhou, J. M. Aller, and R. G. Harley, "Wind speed estimation based sensorless output Maximization control for a wind turbine driving a DFIG,” IEEE Trans. Power Electron., vol. 23, no. 3, pp. 1156-1169, May 2008.

[5]. W. Qiao, G. K. Venayagamoorthy, and R. G. Harley, "Real-time implementation of a STATCOM on a wind farm equipped with doubly fed induction generators,” IEEE Trans. Ind. Appl., vol. 45, no. 1, pp. 98-107, Jan./Feb. 2009.

[6]. Yazdani, "Islanded operation of a doubly-fed induction generator (DFIG) wind-power system with integrated energy storage," in Proc. IEEE Canada Elect. Power Conf., Montreal, QC, Canada, Oct. 25-26, 2007, pp. 153-159.

[7]. W. Qiao and R. G. Harley, "Grid connection requirements and solutions for DFIG wind turbines," in Proc. IEEE Energy Conf., Atlanta, GA, Nov. 17-18, 2008, pp. 1-8.

\section{Chapters in Books:}

[8]. "Focus on 2030: EWEA aims for 22\% of Europe's electricity by 2030,"Wind Directions, pp. 25-34, Nov./Dec. 2006.

Books:

[9]. D. Rastler, "Electric energy storage, an essential asset to the electric enterprise: Barriers and RD\&D needs," California Energy Commission Staff Workshop Energy Storage Technol., Policies Needed Support California's RPS Goals 2020, Sacramento, CA, Apr. 2, 2009.

[10]. 20\% Wind Energy By 2030: Increasing Wind Energy's Contribution to U.S. Electricity Supply, U.S. Department of Energy, Jul. 2008 . 